\title{
AIDS: The general practitioner's concern
}

\author{
ROBERT CAMPBELL, DO
}

All primary care physicians will at some time be consulted about AIDS. The questions involving epidemiology, diagnosis, social impact, prevention, and treatment are endless and we have no choice but to field these inquiries with appropriate answers. This article is directed at primary care physicians with the following considerations: Addressing the HIV/AIDS problem; examining our attitudes about AIDS; taking a thorough history from those at risk for HIV; being aware of findings that make you suspicious of HIV; working up the patient for HIV complications; and advising and counseling the patient of your findings.

Although AIDS is preventable, epidemiologists are predicting multifold increases in full-blown AIDS cases during the next five years and beyond. To date, every state has reported AIDS cases, and nonurban areas now have increasing numbers of persons infected with human immunodeficiency virus (HIV). The future impact of the AIDS epidemic cannot be predicted realistically, but it is obvious that hospitals and special care centers will not be able to handle the vast numbers of seriously ill or terminal AIDS patients. Therefore, primary care physicians can expect to be caring for AIDS patients and to be consulted by patients' families and friends and even communities regarding AIDS and their fear of contagion.

Development of an effective HIV vaccine is still years away. Thus, educating the public about AIDS remains the greatest preventive measure, and the responsibility for this, to a large degree, falls to primary care physicians. The risk of HIV infection increases with frequent sexual contacts or the sharing of contaminated needles with infected persons, by receipt of infected blood or blood products, and for an unborn child with an infected mother. The new standards for blood donors, blood testing, and donor blood treatments have addressed the problems of transfusion, but dealing with the sexual behavior and intravenous drug abuse associated with AIDS is still a formidable task. General practitioners must take a leadership role in this educational effort, not only by educating themselves, but primarily by becoming involved with drug and sex education in schools, communities, places of worship, the work place, and in the media.

Currently, you may not be caring for any AIDS patient or high-risk persons, yet be aware that at least one of your patients potentially has been exposed to HIV through a blood transfusion or some other incident since 1975. You're going to be asked questions about HIV testing. Who should be tested? What does a positive test result mean? Should mass routine screening be done? Does a negative result mean that the person's blood is safe for transfusion? Will the antigen test be more valid? If a person is positive for HIV but completely asymptomatic, what should present management consist of? The questions are numerous and complex and can be confusing, and you need to be accurate in your reponse to patients, to other health care workers, and to the media.

The physician must become aware of the multiple clinical problems presented by the HIV patient, who can be totally asymptomatic or who can have a multitude of symptoms erroneously assumed or diagnosed as a flu, especially in the early stage of illness. When the immune complex is assaulted by $\mathrm{HIV}$, thrombocytopenia, dementia, and meningitis may manifest early. As the disease progresses, other opportunistic infections and their sequelae will become apparent. Fevers of unknown origin, suspicious mouth lesions and unexplained diarrhea, lymphadenopathy, and headaches should be probed carefully.

In most patients, the virus will remain latent 
for years while being capable of transmission to others. Most studies show that once infected with $\mathrm{HIV}$, most persons, if not all, will progress toward increased infectivity and, eventually, immune- or CNS-related problems. Depending on life-styles, general health, and other factors, this process can take many years. Therefore, seropositive patients may have to be counseled and monitored for extended periods. During this time these patients are working, living, playing, and enjoying their lives as they wish; they have freedom to travel, freedom to do most anything they desire, and they are protected by human rights never before equaled in human civilization. Therefore, those with high-risk behavior must be advised repeatedly against spreading the disease to their sex or drug partners.

For many general practitioners, it is easier to avoid AIDS patients altogether than to deal with the emotional conflicts encountered in their care. Fear of contagion provides a convenient and, at times, a publicly "acceptable" excuse. Through becoming well informed, this fear can be easily overcome, not only by physicians, but by patients and communities as well. However, irrational fears based on one's own underlying psychologic conflicts are much more difficult to address. Attitudes about AIDS and HIV-infected patients must be re-evaluated if primary care physicians are to be effective in caring for these patients. The stresses inherent in managing AIDS patients must be acknowledged, and, of course, a degree of apprehension is normal. However, as AIDS becomes more and more of a social problem, it must be accepted that all of us will be handling HIV patients, knowingly or not. By gaining insight into our own irrational fears and attitudes about this disease, we can effect constructive changes.

Becoming knowledgeable about HIV and its peculiarities as well as the immune system and its functional characteristics is paramount for all physicians if they are to be capable of imparting accurate information about AIDS. By understanding these two very important subjects, one can better see why an effective vaccine will be difficult to produce. Because of the HIV becoming a "provirus" spliced into the host cell's chromosome, attempts to develop antiviral medications, immunomodulators, and/or other effective therapies have been difficult and nondefinitive. Even if a vaccine becomes available, everyone's input and educational efforts will be needed to make such a program worthwhile. Remember the government-sponsored swine flu vaccine program? And the hepatitis-B inoculation effort has been very disappointing with regard to the high-risk groups for whom it was initially intended.

AIDS presents a real challenge to all branches of society, especially the medical sector. Misinformation and anxiety levels are excessive and unfortunate. As a result, implementation of public policies to help reduce risks become more difficult. If we as osteopathic general practitioners are to help, we must become knowledgeable about the immune system and about the HIV, its epidemiology, and its consequences. As the public looks to us for leadership, we must be capable of providing accurate information. Effecting life-style changes, especially those involving sexual practices and intravenous drug use, will not be easy, but at this time this is the only real help we can offer toward the prevention of AIDS.

\section{Recognizing high-risk persons}

About three fourths of AIDS patients are homosexual or bisexual men with numerous sexual contacts, and approximately one in every six persons with AIDS has a history of intravenous drug abuse. Female partners of high-risk men are at increased risk. Recipients of blood or blood products between 1975 and 1985 may have been infected; they should be asked about the reason for transfusion, the time and place of transfusion, and the amount of blood used. (Hemophiliacs are well known to their physicians, but they are seen in emergency rooms too.) Children born of mothers with HIV are at extreme risk. At present, undisciplined heterosexuality also is considered to be high-risk behavior. The fact is, anytime an individual's intact blood or body fluids are exposed to the blood or body fluids from an HIV infective, this becomes a risk factor. This does not mean that any one exposure will transmit the virus; it simply means that the person is at risk.

If you see or hear evidence or instinctively feel that more information would be helpful, you should pursue the questioning process in a sincere, helpful, matter-of-fact manner. The subject of approaching the patient with such personal questions has been discussed at every AIDS conference I've attended, and the answer is always the same: If you need specific information, you will have to ask specific questions, because few patients are willing to offer such information.

Another topic concerns the workup for persons who may be concerned about their health but who are frightened to discover their HIV status. Or the physician may have concerns about a particular patient and needs more information to formulate a plan of action. Because of the controversy surrounding the HIV antibody test, a thorough patient workup should be performed; if the findings so indicate, the antibody test should be discussed. A high-risk patient questionnaire, "special attention" physical examination procedures, and a proposed 
TABLE 1. HIGH-RISK PATIENT QUESTIONNAIRE.

To the patient:

The following questions will help to determine whether you have been exposed to any unusual infection, such as hepatitis B, parasites, or human immunodeficiency virus. Be honest in your answers so that we can help you in the best way possible. This information will be held in the strictest of confidence within the laws of this state.

YES NO

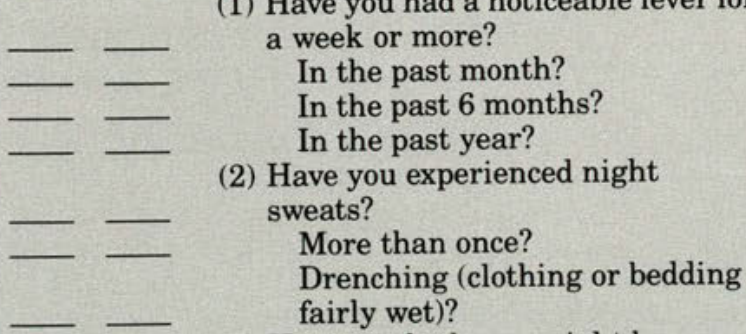

(3) Have you had any weight loss over the past few months?

Intentional? Did you diet or try to lose weight?

More than 10 pounds?

(4) Do you become tired easily? Does it interfere with your work? Does it interfere with your normal activities?

(5) Do you have any allergies to drugs or medicines?

Write in the names of drugs or medicines

(6) Have you had any skin rashes that have not responded to treatment? On your head, face, or neck? On your chest, back, underarms, or abdomen?

In your genital or rectal area? On your arms, hands, legs, or feet?

(7) Have you ever had shingles (herpes zoster)?

(8) Have you ever had genital herpes?

(9) Have you ever had oral herpes? If so, does the herpes recur or heal slowly, or both?

(10) Have you ever had thrush Candida of the mouth?

Candida of the rectum?

Candida of the genital area?

(11) Have you ever had lesions on the side of your tongue?

(12) Have you ever had sore throats? Frequently?

Severe?

Difficult swallowing?

(13) Have you ever had stomach problems? Indigestion?

Pain?

Loss of appetite?

Nausea or vomiting?
(14) Have you ever had frequent episodes of diarrhea?

Daily?

Weekly?

Monthly?

(15) Do you have cramps in your abdomen? Daily? Or how often?

(16) Have you ever noticed lymph nodes (lumps under skin)?

Neck?

Underarm?

Groin?

Other? (Explain)

(17) Have you ever noticed reddish or purplish spots on your skin? Where? (Explain)

(18) Do you bruise easily?

(19) Do you have nosebleeds? Often?

(20) Have you ever had a blood transfusion? For what reason?

When?

Where?

How many pints (units)?

(21) Have you ever donated blood? When?

Where?

For what reason?

(22) Have you ever been told that you have a bleeding disorder?

(23) Do you take any medications for bleeding disorders?

(24) Have you ever noticed blood in your urine?

(25) Have you ever noticed blood in your bowel movement?

(26) Do you have headaches?

Daily?

Severe?

Migraine type?

(27) Do you ever have pain or numbness in your face?

In your arms or hands?

In your legs or feet?

(28) Do you become depressed easily? Have you ever considered suicide?

(29) Do you have mood swings-up one day, down the next?

(30) Are you happy some days, grumpy other days?

(31) Do you have difficulty writing a letter or signing your name?

(32) Do you have any difficulty with vision? Double vision?

Blurry vision?

Spots before your eyes?

(33) Do you have difficulty in concentrating on a subject?

(34) Do you have problems with your memory, (names, faces, etc)?

(35) Have you ever had a seizure?

(36) Have you ever had spells of weakness? In your arms? In your legs? 


(37) Have you had difficulty talking or
pronouncing words?
(38) Does your tongue or gums get sore
or burn?
While lying down?
Is cough productive?
Is cough worse when you breath
deeply?

HIV laboratory screening protocol are presented in Tables 1,2 , and 3, respectively.

I suggest that you consider not putting the patient's name on these highly confidential documents. Rather, devise your own method of coding so that confidentiality becomes paramount.

\section{Clinical findings}

As AIDS spreads, so does our knowledge of the various resultant syndromes. The Centers for Disease Control's classification of AIDS has been revised and probably will be again as more sequelae become apparent.

\section{Initial HIV infection}

Many persons, when they first become infected with HIV, will develop a mononucleosis-like syndrome over a period of several days to several weeks. This is simply the immune system being
(51) Have you ever engaged in sexual intercourse?

(52) Do you have sexual relations on a regular basis?

(53) Have you had sexual relations with more than one person?

(54) Have you ever had sexual relations with a person of your own sex?

(55) Have you ever received, or given, oral sex?

(56) Have you ever received, or given, anal sex?

(57) Have you ever inserted objects into your rectum?

(58) Have you ever had sexual relations with a person who uses, or abuses, drugs?

(59) Have you ever had sex with someone who had hepatitis?

(60) Have you ever had sex with someone who had AIDS or someone who later found out that he had AIDS or was positive for HIV?

(61) Do you use protection when you have sex?

What do you use?

(62) Have you ever used drugs during sex?

(63) Has your sex drive (libido) changed in the past year?

Increased?

Decreased?

(64) Do you have bleeding after you have sex?

(65) Are you content with your sexual behavior at this time?

(66) Is there anything else you would like to discuss?

(If so, please elaborate below). stressed in a vain attempt to eliminate the HIV. As the T4 cells begin to respond and the B cells start producing antibodies, the patient may complain most commonly of fever, headaches, and diarrhea; sweats, lethargy, malaise, myalgias, arthralgias, pharyngitis, anorexia, vomiting, and weight loss also may appear at this time.

In most viral infections (rhinovirus and influenza, for example), the immune system recognizes the problem within three to five days, produces a few or several of these complaints, and usually by days 7 to 10 has the infection under control. With Epstein-Barr virus (mononucleosis), this process takes up to 3 or 4 weeks and literally disables some persons for that period of time. But the HIV is a retrovirus, which splices itself into the T4 cell's chromosome and then is turned on and off as the T4 cell is activated immunologically. During the acute infectious stage, the T4 cells proliferate, T8 
cells and T8 cytotoxic cells (cytotoxic cells are members of the T8 lymphocyte family) increase, B cells try to produce enough as well as the right antibodies, and the patients' associated complaints-fever, headaches, etc. - wax and wane with each immune response.

\section{Later stages of infection}

After the initial infectious stage intensifies, several additional physical findings will become apparent. Of these, generalized lymphadenopathy and splenomegaly are most common. Lymphopenia is followed by atypical lymphocytosis; as the disease progresses to full-blown AIDS, the lymphopenia becomes more permanent. Later in the initial phase, there is an inversion of the $\mathrm{T} 4 / \mathrm{T} 8$ ratio because of an increase in the T8 and T8 cytotoxic cells. The $\mathrm{T} 4$ cell level then begins to decrease as the disease progresses, as do other lymphocytic components.

Antibodies can be detected as early as 19 days or as late as 90 days after onset of infection in the usual responder. ${ }^{1}$ However, exceptions must be considered. One well-documented case seroconverted six days after exposure, and several reports have been filed on patients who were consistently seronegative and in clinically good health despite persistent culture-documented HIV viremia. ${ }^{1}$ Apparently, the HIV couldn't invade these patients' T4 cells in a manner that caused an appropriate immune response.

Neurologic problems have been reported as the first sign of HIV infection in $20 \%$ to $25 \%$ of cases. $^{1}$ This includes several cases in which seroconversion was concurrently present with acute, selflimiting encephalopathy, which was marked by progressive deterioration in mental status over a period of days to weeks followed by a spontaneous recovery. Other patients have had focal CNS signs, including facial nerve palsy or diplegia, and/or weakness and sensory loss in their limbs, all of which were coincident with seroconversion. It must be assumed that as the immune response becomes chaotic in a vain attempt to rid the body of HIV, and along with any direct effects from the HIV itself, some unusual side effects are encountered especially in the CNS.

Of all of the signs and symptoms discussed, the four most commonly seen in patients with HIV infection include fever of unknown origin, lymphadenopathy (usually generalized), intermittent, frequent, or profuse diarrhea, and frequent, constant, or recurrent headaches. Whether observed alone or in combination, the physician should investigate each as to cause and origin. It must be emphasized that these subjective and objective findings are not inevitable consequences of $\mathrm{HIV}$ infection. At least
TABLE 2. PHYSICAL EXAMINATION PROCEDURES FOR SUSPECTED HIV-INFECTED PATIENTS.

Put gloves on, and, giving special attention to the following, perform a head-to-toe examination:

Vital signs

Weight

Temperature (note time of day)

Respirations

General appearance (describe thoroughly)

Skin

Thorough search for inflammatory skin or scalp problems Rashes, lesions, discolorations (describe each)

Lymph nodes

Occipital, auricular, submental, anterior and posterior cervical, axillary, epitracheal, supraclavicular, inguinal, and femoral (be specific as to size and location)

\section{Mucous membranes}

Mouth (look for oral hairy leukoplakia, thrush, lesions, discolorations, secondary infections)

Anal/sigmoid (candidiasis, warts, discolorations, lesions) Vagina (candidiasis, warts, discolorations, lesions)

Fundoscopic examination

Look for cotton wool spots, and/or hemorrhages

Abdominal palpation

Look for nodes, hepatomegaly, splenomegaly

one third of all initial HIV patients who seroconvert do not complain of symptoms. Perhaps their life-styles permit slow progressive HIV activity or their immune responses are simply much slower; therefore, they have few, if any, associated symptoms.

In many of the slow immune responders, an unusual and new lesion, oral hairy leukoplakia, is being described. It arises as immune competence declines; it may be the first indication to both the patient and physician that HIV is active. It results from an Epstein-Barr viral infection that is permitted to proliferate in the face of a progressive immunosuppression.

Oral hairy leukoplakia appears principally on the lateral borders of the tongue as slightly raised, poorly demarcated, striated lesions with a corrugated, or hairy-like, surface. Candida is often harbored between the projections and can be removed by rubbing a tongue blade across the surface. The hairy leukoplakia will not rub off. These lesions, which range in size from millimeters to centimeters, may be asymptomatic, and the patient may not be aware of their presence. The condition is common in male homosexuals and usually is one of many immune deficient problems. However, in 
TABLE 3. LABORATORY EVALUATION OF SUSPECTED HIV PATIENTS.

Complete blood count

Leukopenia leukocytes, $<4,000 /$ cu $\mathrm{mm}$ ) is usual with HIV in the later stages.

Differential count usually shows lymphopenia $(<25 \%$ lymphocytes).

Mild-to-moderate anemia (hematocrit, $<35 \%$, hemoglobin, $<12 \mathrm{~g} / \mathrm{dL}$ ) is present.

Platelet count is mildly reduced in most cases (drastically reduced in some).

Erythrocyte sedimentation rate determination (Westergren method)

The ESR is almost always elevated to $70 \mathrm{~mm} / \mathrm{h}$ or more in the actual HIV infection stage.

Blood chemistry studies

Pay particular attention to low levels of cholesterol and albumin and elevated levels of triglycerides, globulin, and liver enzymes. Serum electrolyte (sodium, potassium, chloride) values will be depressed if diarrhea is profuse.

\section{Skin testing}

Mumps, Candida, Trichophyton, and PPD results all may be suppressed or negative. These are good tests of the patient's immune system.

\section{Stool cultures}

Results can be mixed, but pay special attention to the presence of Salmonella, Shigella, Campylobacter, Entamoeba histolytica, Giardia lamblia, and Cryptosporidium.

\section{Serologic evaluation}

Of course, HIV antibody testing is foremost here, but remember that the patient may be in the pre-positive stage. Other antibodies to be concerned about include those for hepatitis A or B, cytomegalovirus, Epstein-Barr virus, and syphilis. ANA and RA immune complexes may be under way.

\section{HIV cultures}

Case reports in which the antibody test was negative but cultures showed HIV viremia have been filed.

\section{Microbiologic evaluation}

This involves urine, blood, throat and lungs in induced or lavaged specimens. Use culture methods to reveal cytomegalovirus and Epstein-Barr virus; both will show up in more than $80 \%$ of HIV infectives. Induced sputum or bronchial lavage may reveal Pneumocystis carinii, tuberculosis, or both. Biopsy of discolorations may reveal Kaposi's sarcoma.

\section{Immunologic evaluation}

The lymphocyte count is reduced, the T4/T8 ratio is reversed, and the immunoglobin profile discloses increased values.

\section{Radiologic studies}

These may be unremarkable. On the chest x-ray, look for interstitial, alveolar, or diffuse infiltrates from Pneumocystis carinii pneumonia, cytomegalovirus, tuberculosis, or fungi. The barium swallow may demonstrate esophageal ulcerations Candida. Abdominal CT scanning may reveal hepatomegaly, splenomegaly, or retroperitoneal lymphadenopathy. CT scanning of the head may demonstrate the lesions of toxoplasmosis or herpetic encephalitis. the past few years heterosexual men and women who presented themselves to physicians for other reasons have had oral hairy leukoplakia found incidentally. ${ }^{2}$ In some patients the lesion may come and go spontaneously, be triggered by stress, and become more permanent as immunosuppression progresses.

\section{Complications of AIDS}

Pneumocystis carinii pneumonia (PCP) continues to be the most common of the more serious pulmonary manifestations in HIV infection. PCP accounts for $80 \%$ of pneumonias in patients who test positive for $\mathrm{HIV}^{3} \mathrm{PCP}$ is probably a reactivation of latent infection acquired in childhood because $60 \%$ or more of all children have antibodies to Pneumocystis carinii by age 4 . As HIV infection progresses, these patients may present with a dry cough and dyspnea or with fever and nightsweats with few pulmonary symptoms. The onset is usually gradual, as mild symptoms progress over a 4 to 6 month period to symptoms severe enough to consult a physician. Treatment is detailed in Table 4 .

Tuberculosis is another common finding in patients presenting with pulmonary complaints due to immune deficiency. This is especially true of immigrant populations whose culture has a high rate of tuberculosis. Persons who have active tuberculosis due to immune deficiency will usually develop full-blown AIDS within a year.

Active pulmonary fungal infection may also be present in patients with a suppressed immune system and, if they test positive for HIV, this qualifies for a diagnosis of full-blown AIDS.

Kaposi's sarcoma occurs much less frequently in the heterosexual epidemiology HIV than in the homosexual epidemiology and is now considered to be the consequences of excessive growth lymphokines. This results from confusion in the immune system's responses toward not only the HIV, but other viral and opportunistic infections as well. When such brownish-purplish lesions are encountered anywhere in the skin or mucous membranes, the examiner should consider this as an ominous sign of confused immune activity, usually toward multiple infectious agents. It seems that once the lymphokine growth factor gets turned on from multiple frequent stimuli (as in HIV infection), it can't reverse itself and Kaposi's sarcoma is one of the consequences. As research continues, I'm sure there will be other identified sequelae of this abnormal mechanism in AIDS.

\section{Diagnosis}

The workup for any suspicious finding that could 


\section{The benefit of antianginal profection plus safefy...}

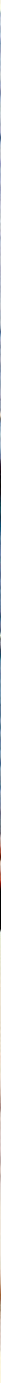

\section{CAR DIZFM: \\ A

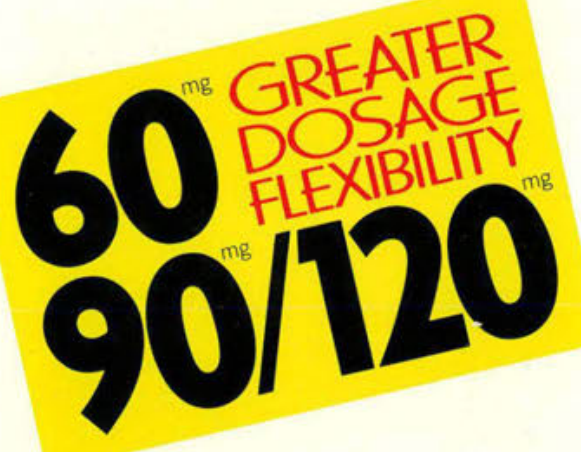

A remarkable safety profile $e^{1-6}$

The low incidence of side effects with Cardizem allows patients to feel better.

Profection against angina attacks ${ }^{1,5,7-9}$

The predictable efficacy of Cardizem in stable exertional* and vasospastic angina allows patients to do more.

\section{A decrease in myocardial oxygen demand} Resulting from a lowered heart rate-blood pressure product ${ }^{5}$

\section{Compatible with other antianginals ${ }^{6+}$}

\section{Safe in angina with coexisting hypertension, COPD, asthma, or PVD ${ }^{13,5,6}$}

"CARDIZEMs (dilticzem HCI) is indicated in the treatment of angina pectoris due to coronary artery spasm and in the
manogement of chronic stable angina (classic effort-associated angina) in patients who cannot tolerate therapy with management of chronic stable angina (classic effort-associated angina) in patients who cannot tolest
beto-blockers and/or nitrates or who remain symptomatic despite adequate doses of these agents. 


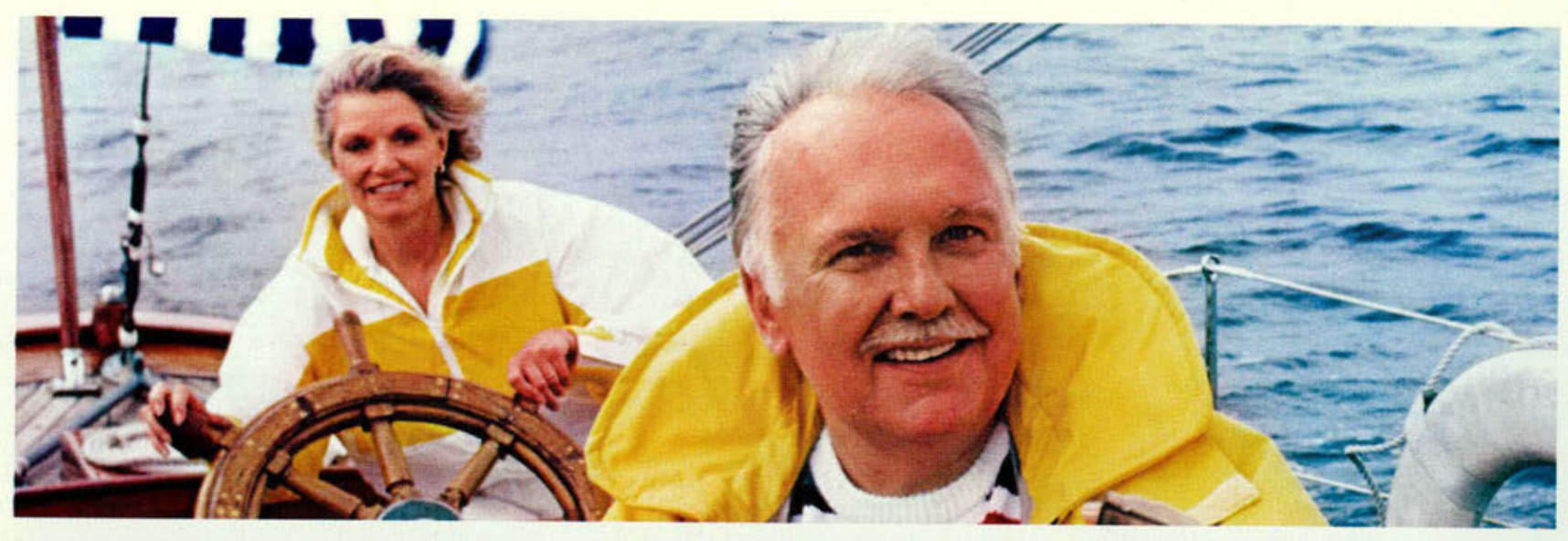

\section{CARDIZEM A diltiazem HCl/Marion \\ PLUS SAFETY}

Usual maintenance dosage range: 180-360 mg/day BRIEF SUMMARY

\section{Professional Use Information}

\section{CARDIZEM $^{\circ}$}

$30 \mathrm{mg}, 60 \mathrm{mg}, 90 \mathrm{mg}$, and $120 \mathrm{mg}$ Tablets

CONTRAINDICATIONS

CARDIZEM is contraindicated in (1) patients with sick sinus syndrome except in the presence of a functioning ventricular pacemaker, (2) patients with second- or third-degree AV block except in the presence of a functioning ventricular pacemaker, (3) patients with hypotension (less than $90 \mathrm{~mm} \mathrm{Hg}$ systolic), and (4) patients who have demonstrated hypersensitivity to the drug. WARNINGS

Cardlac Conduction. CARDIZEM prolongs AV node

Cardlac Conduction. CARDIZEM prolongs AV node
refractory periods without significantly prolonging sinus

refractory periods without significantly prolonging sinus
node recovery time, except in patients with sick sinus

syndrome. This effect may rarely result in abnormally slow

heart rates (particularly in patients with sick sinus

syndrome) or second- or third-degree AV block (six of 1,243

patients for $0.48 \%$ ). Concomitant use of diltiazem with

beta-blockers or digitalis may result in additive effects on

cardiac conduction. A patient with Prinzmetal's angina

developed periods of asystole (2 to 5 seconds) after a

政

2. Congestive Heart Fallure. Although diltiazem has a negative inotropic effect in isolated animal tissue

emodynamic studies in humans with

in cardian index function have shown a redion

in cardiac index nor consistent negative effects on

a with impaired ventricular function is very lim patients whould be exercised when using the vrug in such paution

3.

3. Hypotension. Decreases in blood pressure associa

symptomatic hypotension.

4. Acute Hepatic Injury. In rare instances, significant

elevations in enzymes such as alkaline phosphatase, LOH,

SGOT, SGPT, and other phenomena consistent with acute hepatic injury have been noted. These reactions have hepatic injury have been noted. These reactions have

relationship to CARDIZEM is uncertain in most cases, but relationship to CARDIZEM is uncertain in
probable in some. (See PRECAUTIONS.)

\section{PRECAUTIONS}

General. CAROIZEM (diltiazem hydrochloride) is extensively metabolized by the liver and excreted by the kidneys and in bile. As with any drug given over prolonged periods, laboratory parameters should be monitored at regular intervals. The drug should be used with caution in patients with impaired renal or hepatic function. In subacute and chronic dog and rat studies designed to produce toxicity, high doses of diltiazem were associated with hepatic damage. In special subacute hepatic studies, oral doses of $125 \mathrm{mg} / \mathrm{kg}$ and higher in rats were associaled with hislological changes in the liver which were reversible when the drug was discontinued. In dogs, doses of $20 \mathrm{mg} / \mathrm{kg}$ were also associated with hepatic changes; however these changes were reversible with continued dosing.

Dermatological events (see ADVERSE REACTIONS section) may be transient and may disappear despite continued use of CARDIZEM. However, skin eruptions progressing to erythema multiforme and/or exfoliative dermatitis have also been infrequently reported. Should a dermatologic reaction persist, the drug should be discontinued.

Drug Interaction. Due to the potential for additive effects, caution and careful titration are warranted in patients receiving CARDIZEM concomitantly with any agents known to affect cardiac contractility and/or conduction. (See WARNINGS. Pharmacologic studies indicate that there may be additive effects in prolonging AV conduction when using beta-blockers or digitalis concomitantly with CAROIZEM. (See WARNINGS.) As with all drugs, care should be exercised when treating patients with multiple medications. CARDIZEM undergoes bio- transformation by cytochrome P-450 mixed function oxidase. Coadministration of CAROIZEM with other agents which follow the same route of biotransformation may result in the competitive inhibition of metabolism. Dosages of similarly metabolized drugs, particularly those of low therapeutic ratio or in patients when starting or stopping concomitantly administered CAROIZEM when starting or stopping concomitantly administe Beta-blockers: Controlled and uncontrolled domestic studies suggest that concomitant use of CARDIZEM and beta-blockers or digitalis is usually well tolerated. Available data are no treatment, particularly in patients with left ventricular dysfunction or cardiac conduction abnormalities. Administration of CARDIZEM (diltiazem hydrochloride) concomitantly with propranolol in five normal volunteers resulted in increased propranolol levels in all subjects and bioavailability of propranolol was increased approximately $50 \%$. If combination therapy is initiated or withdrawn in conjunction with propranolol, an adjustment in the propranolol dose may

Clmetidline: A study in six healthy volunteers has shown a significant increase in peak diltiazem plasma levels $(58 \%)$ and area-under-the-curve $(53 \%)$ after a one-week course of cimetidine at $1,200 \mathrm{mg}$ per day and dittiazem $60 \mathrm{mg}$ per day. Ranitidine produced smaller, nonsignificant increases. The effect may be mediated by cimetidine s known inhibition of hepatic cytochrome $P-450$, the enzyme system probably responsible for the first-pass metabolism of dirtiazem. Patients currently receiving diltiazem therapy should be carefully monitored for a change in pharmacological effect when initiating and discontinuing therapy with cimetidine. An adjustment in the diltiazem dose may be warranted. healthy male subjects increased plasma digoxin concentrations digoxin levels in 12 patients with coronary artery disease. Since there have been conflicting results regarding the effect of digoxin levels, it is recommended that digoxin levels be monitored when initiating, adjusting, and discontinuing CAROIZEM therapy to avoid possible over-or under-digitalization. (See WARNINGS.) Carcinogenesis, Mutagenesis, Impairment of Fertillty. A 24-month study in rats and a 21-month study in mice showed no evidence of carcinogenicity. There was also no mutagenic
response in in vitro bacterial tests. No intrinsic effect on fertility was observed in rats.

Pregnancy. Category C. Reproduction studies have been conducted in mice, rats, and rabbits. Administration of doses ranging from five to ten times greater (on a $\mathrm{mg} / \mathrm{kg}$ basis) than the daily recommended therapeutic dose has resulted in embryo and fetal lethality. These doses, in some studies, have been reported to cause skeletal abnormalities. In the perinatal/ postnatal studies, there was some reduction in early individual pup weights and survival rates. There was an increased incidence There are no well-controlled studies in pregnant women; therefore, use CARDIZEM in pregnant women only if the potential benefit justifies the potential risk to the fetus.

Nursing Mothers. Diltiazem is excreted in human milk. One mate serum levels. If use of CAROIZEM is deemed essential, an alternative method of infant feeding should be instituted. Podlatric Use. Safety and effectiveness in children have not been established.

\section{ADVERSE REACTIONS}

Serious adverse reactions have been rare in studies carried out to date, but it should be recognized that patients with

impaired ventricular function and cardiac conduction abnormalilies have usually been excluded.

作 reactions reported during CARDIZEM therapy was not greater sufficient, however, to predict the eflects of concomitant

Digltalls: Administration of CAROIZEM with digoxin in 24 approximately 20\%. Another investigator found no increase in of stillibirths at doses of 20 times the human dose or greater. report suggests that concentrations in breast milk may approx
$\mathbf{R}_{\mathbf{X}}$

$$
\begin{gathered}
\text { Candigemin } \\
\text { (diltiazem }
\end{gathered}
$$

$\square 60 \mathrm{mg} \quad \square 90 \mathrm{mg}$

$\square 120 \mathrm{mg}$

Siq: tid

than that reported during placebo therapy.

The following represent occurrences observed in clinical studies which can be at least reasonably associated with the pharmacology of calcium influx inhibition. In many cases, the relationship to CARDIZEM has not been established. The most common occurrences as well as their frequency of presentation are: edema (2.4\%), headache $(2.1 \%)$, nausea (1.9\%), dizziness $1.5 \%)$, rash (1.3\%), asthenia (1.2\%). In addition, the following

Cardiovascular: Angina, arrhythmia, AV block (first degree), AV block (second or third degree-see conduction warning), bradycardia, congestive heart fallure, flushing.

Nervous System: Amnesia, depression, gait abnormality. Amnesia, depression, gait abnormality,
hallucinations, insomnia, nervousness, hallucinations, insomnia, nervousn
paresthesia, personality change.$$
\text { somnolence, }
$$

Gastrointestinal: Anorexia constipation, diarrhea, dysgeusia, dyspepsia, mild elevations of alkaline phosphatase, SGOT, SGPT, and $\mathrm{LDH}$ (see hepatic warnings), vomiting.

weight increase.

urticaria, pruntus, photosensitivity. urticaria.
Amblyopia, CPK elevation, dyspnea, epistaxis, eye irritation, hyperglycemia nasal congestion, nocturia, osteoarticular pain, polyuria, sexual difficulties.

The following postmarketing events have been reported infrequently in patients receiving CAROIZEM: alopecia, gingival hyperplasia, erythema multiforme, and leukopenia. However, a therapy is yet to be established.
Issued 6/87 See complete Professional Use Information before prescribing.

References: 1. Schroeder JS: Mod Med 1982,50(Sept): 94 116. 2. Cohn PF, Braunwald E: Chronic ischemic heart disease, in Braunwald E (ed): Heart Disease: A Textbook of Cardiovascular Medicine ed 2. Philadelphia, WB Saunders Co, 1984, chap 39. 3. O'Rourke RA: Am J Cardiol 1985:56:34H-4OH. 4. McCall D, Wolsh RA. Frohlich ED, et al: Curr Probl Cardiol 1985; 10(8):6-80. 5. Frishman WH Charlap S, Goldberger J, ef al: Am J Cardiol 1985;56:41H. 46H. 6. Shapiro W: Consultant 1984:24(Dec):150-159. 7. O'Hara MJ, Khurmi NS, Bowles MJ, ef al: Am J Cardiol 1984;54:477-481. 8. Strauss WE, Mcintyre KM, Parisi
et al: Am J Cardiol 1982; 49.560-566. 9. Feldman RL, Pepine W, Whittle J, et al: Am J Cardiol 1982:49:554-559. 
relate to HIV should include a thorough physical examination for other signs of immunosuppression, such as enlarged lymph nodes or cutaneous infections (Table 2). Laboratory studies to evaluate the immune system and its response to antigens are very useful (Table 3 ).

Be ever alert to infection control practices, such as sterilizing instruments and wearing gloves. With a virus like HIV, and with the majority of infected persons totally asymptomatic and unaware of their status, you must handle all patients as if they were infected. If you wait until making an HIV diagnosis to practice infection control, you're doing both yourself and your patients a disservice.

It would be so simple to order the HIV antibody test as soon as the physician suspects the disease. However, because of the controversy surrounding the test (false-negative and false-positive results, problems with confidentiality, and employment as well as social issues), some patients may be reluctant to be tested for their HIV status. Some may be insulted just by having the subject introduced. Inquiry into sexual behavior also can be very sensitive. In fact, a number of these patients may not return for another visit.

The best approach is to explain to the patient that the findings indicate problems that occur in individuals who are immunosuppressed, and that you would like to perform a complete physical examination to check for other signs of immunosuppression. Also, tell the patient that a laboratory evaluation of his immune status, including a complete blood count and sedimentation rate and T4/ T8 ratio determinations, is necessary. If the patient is comfortable with having the HIV antibody test, tell him that you will follow the rules of confidentiality within the limits of the laws where you practice. If the laboratory results are negative for HIV, reassure the patient and search for other causes of the pertinent findings.

\section{Management}

After confirming the diagnosis, the patient must be notified that he is infected with the HIV virus and that this also means that he is infectious. Then explain the steps that the patient must follow to prevent spread to anyone else. Reassure the patient that not everyone infected with HIV develops full-blown AIDS; patients with chronic lymphadenopathy, AIDS-related complex (ARC), or fullblown AIDS represent less than $10 \%$ of those infected with the virus. ${ }^{1}$ Discuss the modifications that he must make in his life-style to ensure that his immune system remains as intact as possible. These include eliminating stress, getting a good night's rest, avoiding recreational drugs, eating nu-

\begin{tabular}{|c|c|c|c|}
\hline Therapy & Dosage & $\begin{array}{l}\text { Major } \\
\text { toxicity }\end{array}$ & \\
\hline $\begin{array}{l}\text { Trimethoprim- } \\
\text { sulfamethox- } \\
\text { azole (TMP-SMZ) } \\
\text { (Bactrim, } \\
\text { Septra, et al) }\end{array}$ & $\begin{array}{l}20 \mathrm{mg} \text { TMP, } \\
100 \mathrm{mg} \mathrm{SMZ} \\
\text { per } \mathrm{kg} / \mathrm{d} \text {; in } \\
\text { four doses IV } \\
\text { or PO; for } 2 \text { to } \\
3 \text { wks }\end{array}$ & $\begin{array}{l}\text { Neutropenia, } \\
\text { thrombocyto- } \\
\text { penia, rash } \\
\text { hepatitis, azo- } \\
\text { temia }\end{array}$ & $\begin{array}{l}\text { Consider: } \\
\text { Toxicity can } \\
\text { devel op in } \\
7-14 \text { days. You } \\
\text { may have to } \\
\text { switch to pen- } \\
\text { tamidine for } \\
\text { another } 7-14 \\
\text { days. Monitor } \\
\text { CBCs, plate- } \\
\text { lets, creatine }\end{array}$ \\
\hline $\begin{array}{l}\text { Pentamidine } \\
\text { isethionate } \\
\text { (Pentam 300) }\end{array}$ & $\begin{array}{l}4 \mathrm{mg} / \mathrm{kg} \text { once } \\
\text { daily; } 1 \text { to } 2 \\
\text { hrs IV infu- } \\
\text { sion; for at } \\
\text { least } 2 \text { wks; } \\
\text { IM route is } \\
\text { not recom- } \\
\text { mended }\end{array}$ & $\begin{array}{l}\text { Neutropenia, } \\
\text { thrombocy- } \\
\text { topenia, azo- } \\
\text { temia, hepati- } \\
\text { tis, hypogly- } \\
\text { cemia, hypo- } \\
\text { tension diabe- } \\
\text { tes (rare) }\end{array}$ & $\begin{array}{l}\text { Consider: } \\
\text { Toxicity can } \\
\text { develop in } \\
7 \text {-14 days. You } \\
\text { may have to } \\
\text { switch back } \\
\text { to TMP-SMZ } \\
\text { for another } \\
\text { course. } \\
\text { Monitor } \\
\text { CBC's, plate- } \\
\text { lets, creatine }\end{array}$ \\
\hline
\end{tabular}

tritious foods, and engaging in regular, noncompetitive exercise. And, of course, regular clinical follow-up visits to keep abreast of any complications that may arise are necessary. Explain to the patient that his health status has now become a life and death priority, whereas before many other activities may have been considered more important.

If the patient is already immunosuppressed, has had a bout with Pneumocystis carinii pneumonia, or has severe lymphadenopathy, fatigue, and other signs and symptoms of HIV-related disease, you should offer the option of Zidovudine (formerly AZT) therapy and participation in prophylactic treatment programs if any are available. Despite our increased knowledge and appreciation for this disease, all we can do at this time is shadow box with it with ineffective treatments.

Speaking of treatment, on numerous occasions I have heard, or read, the word cure being used in regard to AIDS. I would like to address the use of this word in the strongest terms. A cure for AIDS would require the following: (1) Any growth of the HIV must be biologically halted; (2) all HIV infections must be eliminated entirely from the body; and (3) any damage to the immune system, as well as to organ systems, must be reversed, with return of these systems to normal, healthy status. There is not now, nor, in my opinion, will there ever be any such cure for AIDS. The only effective tool available at this time is prevention, and, of course, this 
will never be accomplished completely. The word cure should be eliminated from the AIDS vocabulary.

Notwithstanding agressive and intense efforts to slow progression of HIV, most patients eventually will develop uncontrollable opportunistic infections, neurologic sequelae, or neoplasms. Up to $50 \%$ of patients diagnosed as having full-blown AIDS (according to the Centers for Disease Control's criteria) will die within two years. ${ }^{4}$ And $60 \%$ of those who survive their initial hospitalization will spend $30 \%$ of their life expectancy incapacitated in an acute-care setting.

\section{Summary}

HIV infection and its multiple ramifications, including the terminal condition called AIDS, represent a real challenge to all primary care physicians. Predictions about the incidence of AIDS cases have been fairly accurate, and there is no reason to doubt the current estimates of one to two million HIV infectives within the U.S. These walking timebombs are living a life of freedom while passing the virus on to anyone willing to share their needles or their sexual intimacies. If the number of
AIDS cases continues to double each year, it is easy to understand how overwhelming this disease can be in a very short period of time. As caring physicians, your continued interest in learning as much as possible about HIV/AIDS will be your investment in your practice future when this disease appears at your office. You will be seeing AIDS patients and you will be expected to participate in their care. And, you will be examining patients who are HIV infected while you and they are unaware of their status. This is a real challenge, and we must be prepared for it.

1. Selwyn PA: AIDS: What is now known. Hosp Prac, September 15, 1986, pp 119-153.

2. A new lesion in potential AIDS victims. Emer Med, August 15, 1987, pp 97-102

3. Mills J: Current topics in infectious diseases. Mod Med, October 1987, pp 92-102.

4. Mills J: Pneumocystis pneumonia in AIDS diagnosis and treatment. Mod Med, October 1987, pp 92-102.

Dr Campbell is in solo practice and is on the staff of St. MaryCorwin Hospital, Pueblo, Colo.

Reprint requests to Dr Campbell, 4491 Bent Brothers Blvd, Colorado City, CO 81019. 